\title{
Exame Nacional de Desempenho dos Estudantes na visão de líderes formais
}

\author{
Marcleide Maria Macedo Pederneiras* \\ Jorge Expedito de Gusmão Lopes** \\ José Francisco Ribeiro Filho *** \\ Marcos Gilson Gomes Feitosa $* * * *$
}

\section{Resumo}

Esta pesquisa teve como objetivo evidenciar a ótica de duas líderes formais sobre fatores que incidiram no resultado do Exame Nacional de Desempenho dos Estudantes (ENADE) de uma Instituição de Ensino Superior (IES). A pesquisa buscou construir um caminho metodológico alicerçado em uma pesquisa de natureza qualitativa, de caráter exploratório, caracterizada como um estudo de caso. A amostra dos sujeitos foi apoiada na técnica "Bola de Neve" (snowball sampling); para tanto, foram selecionadas a Diretora de Avaliação e Planejamento e a coordenadora da Comissão Própria de Avaliação, ambas responsáveis diretas por todas as fases do ENADE, da IES em estudo. Na coleta de dados foi utilizada a entrevista não estruturada, e na análise dos dados utilizou-se análise do discurso, onde os dados foram sistematicamente comparados, considerando pontos destacados pelas entrevistadas, como repetições de expressões, divergências, palavras, ideias, reflexões e posicionamentos acerca do objeto do estudo. 0 contexto possibilitou identificar alguns fatores que interferem no resultado do ENADE. Desta maneira, os achados reforçam que, dentre os muitos fatores importantes para obter-se um resultado satisfatório no ENADE, a sensibilização, a motivação e o compromisso dos alunos com o ENADE são tidos como os mais significativos na visão das líderes entrevistadas.

Palavras-chave: Avaliação. Sensibilização. Motivação.

Doutoranda, Programa de Pós-Graduação em Administração da Universidade Federal de Pernambuco (PROPAD/UFPE); Professora, Universidade Federal da Paraíba (UFPB). E-mail: marcleide@gmail.com

* PhD, Administração da Educação, University of Miami; Professor do Programa de Pós-Graduação em Ciências Contábies (PPGCC), UFPE. E-mail: professorjorgelopes@gmail.com

... Doutorado em Contabilidade, Universidade de São Paulo (USP); Professor, PPGCC/UFPE e do curso de Ciências Contábeis. E-mail: francisco.ribeiro@pq.cnpq.br

... Doutorado, Educação, Universidade de São Carlos, SP; Professor, PROPAD/UFPE e do curso de Administração. E-mail: marcosfeitosa@ufpe.br 


\section{Enade Exam In The Perspective Of Formal Leaders Abstract}

This research, aimed to highlight the perspective of two formal leaders, focused on factors that result in an IES ENADE. The study aimed to construct a methodological approach grounded in a qualitative exploratory research, characterized as a case study. The sample of subjects was supported by the technical "Snowball" (snowball sampling), for both subjects selected for the research were the Director of Evaluation and Planning and the coordinator of the committee for assessment, (both directly responsible for all phases of ENADE, IES in the study). The data collection were unstructured interviews and data analysis to discourse analysis, where data were systematically compared, considering the points highlighted by interviewees as repetitions of expressions, differences, words, ideas, reflections and positions about the object of study. The context made it possible to identify some factors that affect the results of ENADE. Thus, the findings suggest that among the many important factors to obtain a satisfactory result in ENADE, awareness, motivation and the commitment of students with ENADE are considered as most significant in the view of the leaders interviewed.

Keywords: Evaluation. Sensitiveness. Motivation.

\section{Examen Nacional de Desempeño de los Estudiantes según la visión De Lideres Formales Resumen}

Esta investigación tiene por objeto destacar la perspectiva de dos líderes formales sobre factores que afectaron el resultado del ENADE (Examen Nacional de Desempeño de Estudiantes, creado por el Ministerio de Educación brasileño) de una IES (Institución de Educación Superior). EI estudio trata de construir una metodología basada en una investigación cualitativa, de tipo exploratorio, que se caracteriza como un estudio de caso. La muestra de los sujetos se apoyó en la técnica denominada "Bola de nieve" (snowball sampling), para la cual se seleccionaron la Directora de Evaluación y Planificación y la coordinadora de la Comisión Propia de Evaluación, ambas responsables directas por todas las fases del ENADE, de Ia IES en estudio. En la recolección de datos se utilizó la entrevista no estructurada y en el análisis de datos, el análisis del discurso, donde los datos se compararon de forma sistemática, teniendo en cuenta los puntos que los entrevistados destacaron, tales como repeticiones de expresiones, divergencias, palabras, ideas, reflexiones y posiciones sobre el objeto del estudio. El contexto permitió identificar algunos factores que afectan el 
resultado del ENADE. Así, los resultados refuerzan que, entre los factores importantes que existen en busca de un resultado satisfactorio en el ENADE, la sensibilización, la motivación y el compromiso de los estudiantes con el ENADE son considerados como los más importantes según la visión de los líderes entrevistados.

Palavras clave: Evaluación. Sensibilización. Motivación.

\section{Introdução}

No contexto do estudo, deve-se inicialmente ter a compreensão com relação à implementação e à aplicabilidade do Exame Nacional de Desempenho dos Estudantes (ENADE), um dos componentes da Avaliação Institucional regulamentada pelo Instituto Nacional de Estudos e Pesquisas Educacionais Anísio Teixeira (INEP), do Ministério da Educação (MEC), que tem por objetivo o aperfeiçoamento das atividades acadêmicas.

O ENADE é um dos instrumentos para dar a sustentação da qualidade do sistema de educação superior.

Desse modo, cabe aos "líderes formais" envolvidos no processo, aqui representados pela Diretora de Avaliação e Planejamento, ligada à Pró-Reitoria de Planejamento (PROPLAN) e à coordenadora da Comissão Própria de Avaliação (CPA), de uma Instituição de Ensino Superior (IES), qualificar analiticamente os resultados obtidos no ENADE de 2008, no âmbito da instituição em estudo.

Com a análise desses líderes formais/atores envolvidos, reunem-se subsídios com vistas a buscar soluções para os possiveis problemas, assim como a disponibilização das informações, que, reunidas com informações de futuros estudos, podem contribuir para uma discussão mais aprofundada sobre os dados obtidos no conjunto da aplicação do processo.

Desta forma, com a realização deste estudo, serão depreendidos os fatores relacionados a uma maior conscientização, tendo em vista a qualidade formal dos envolvidos nessa investigação e suas atividades acadêmicas diretamente relacionadas com análise qualitativa do ENADE, na busca contínua de uma melhoria nos resultados advindos desse exame.

\section{Definição do problema}

Diante da necessidade acima referida, buscar-se-á nas líderes formais entrevistadas a compreensão opinativa dos diversos fatores do processo que elas administram e analisam no seu todo, emergindo como foco de interesse da pesquisa a questão: Qual a visão das líderes formais sobre fatores que incidiram no resultado do ENADE da IES? 


\title{
Referencial teórico
}

\section{Avaliação institucional}

De acordo com as informações contidas no site do Centro Federal de Educação Tecnológica de Pelotas (CEFET-RS) ([2005?]), o sistema de avaliação em prática no Brasil entre os anos de 1995 e 2002, com base no PROVÃO, muito embora tenha conseguido sucessos significativos, foi substituido, a partir de 2004, pelo SINAES que possui aspectos importantes não adotados no sistema anterior. As deficiências que estavam presentes na forma de avaliação anterior e que o SINAES procura minorar são o fato de que estas contemplavam poucas as particularidades de cada instituição.

Criado pela Lei $n^{\circ} .10 .861$ (BRASIL, 2004) e regulamentado pela Portaria Ministerial nº 2.051 (BRASIL, 2004), o Sistema Nacional de Avaliação da Educação Superior (SINAES), é estruturado em três pilares básicos de avaliação: Avaliação Institucional (AVALIES); Avaliação dos Cursos de Graduação (ACG); Avaliação do Desempenho dos Estudantes (ENADE).

Dias Sobrinho (1996, p. 15) afirma que a avaliação institucional tem força instrumental e densidade política, sendo mais do que uma questão meramente técnica:

\begin{abstract}
Ainda que também seja uma questão técnica, muito mais importantes são a sua ação e seu significado político. As discussões técnicas que lhe dizem respeito são o conteúdo previsivel e superficial de questões de fundo que têm a ver com destinos da universidade e com o desenvolvimento da sociedade humana. Em outras palavras, a avaliação institucional é um campo de disputas que ultrapassam as questões mais aparentes e formais da organização e do gerenciamento das instituições educativas.
\end{abstract}

Goldemberg (1992) descreve que a avaliação vem sendo definida no País como instrumento competente para promover a melhoria do ensino e o desenvolvimento da produção científica nas universidades.

A avaliação pressupõe a aquisição de subsídios para analisar a distância entre a realidade e o que se deseja, permitindo a realização de ações direcionadas para modificar a situação de cada IES, direcionando as ações para o desejado. A avaliação pode proporcionar a criação urgente de propostas no próprio planejamento institucional (OLIVEIRA, 1999).

\section{A cultura de avaliação}

A avaliação institucional surge como um movimento importante, uma alternativa para a auto-reflexão. Esta importância se dá em no âmbito nacional, sendo dirigida por discussões, propostas e projetos, agregando valores, demonstrando caráter formativo, e 
vista como instrumentos de gestão. A autoavaliação é um ganho para a universidade, possibilitando o pensar de modo sistemático sobre a natureza da instituição e o seu papel na atualidade, conduzindo à busca da coerência entre o que se diz e o que se faz, proporcionando a reflexão sobre a manutenção ou modificação de prioridades.

Este paradigma de avaliação para espaço para o compromisso com o envolvimento, institucionalizado, com o diagnóstico a ser realizado, gradualmente, atende todas as dimensões e atores envolvidos no processo de construção da qualidade da instituição.

A avaliação institucional em instituições de ensino nos leva à ação de erigir informações sobre a realidade da instituição, a fim de utilizá-las para tomada de decisões na busca da excelência da atividade-fim.

De acordo com Trigueiro (1995), a abrangência das técnicas avaliativas leva em consideração o conjunto de processos psicológicos e sociais que perpassam a instituição no âmbito acadêmico ou no administrativo.

Para inserir o processo de avaliação institucional nas universidades, são necessárias medidas que motivem a participação dos atores envolvidos, pois há muita resistência por parte desses atores, tendo em vista que eles sentem receios pela expectativa do uso dos resultados e das tomadas de decisões a que eles estão vinculados.

Tais resistências podem surgir de diversas maneiras e, além, de influenciar na participação da comunidade acadêmica nos procedimento avaliativos, podem gerar tensões relacionadas às propostas de plano de avaliação, o que acaba por inviabilizar algumas etapas do processo. Ainda, tais resistências podem sugerir necessidade de avanço no desenvolvimento da cultura de avaliação.

Quando é identificado esse tipo de necessidade, agir com desprezo pode comprometer o processo.

Em função da experiência de avaliar e ser avaliado, é de se esperar que os setores da instituição que passem por menos experiência tenham menor avanço na cultura.

Segundo Ristoff (1999), a cultura de avaliação pode ser entendida como um conjunto de valores acadêmicos, atitudes e formas coletivas resultantes das funções existentes na universidade. Essa afirmação é útil para se compreender a cultura de avaliação como relacionada às práticas da comunidade acadêmica, em especial à prática avaliativa.

Para ajudar na aplicação da avaliação dentro da comunidade institucional, precisa-se atentar para aplicação dos princípios e valores proclamados, principalmente, 0 princípio da não punição, pois dessa maneira a comunidade percebe seu objetivo primeiro, que é o diagnóstico da realidade para buscar a melhoria. 
Para Faúndez (1999), a cultura é um processo associado à ideologia organizacional, responsável pela implantação de normas, valores e crenças na comunidade. Para implantar a cultura de avaliação, necessário se faz vencer as resistências e os temores, tais como, a desconfiança no sistema e as experiências e avaliação passadas que destoam do atual. Para o autor, é importante considerar os temores gerados pela expectativa do uso dos resultados para fins que não os propostos para a avaliação. Alguns fatores importantes são considerados para o desenvolvimento da cultura de avaliação: esclarecimento sobre o que é a autoavaliação, a sensibilização dos atores envolvidos, e o uso dos resultados.

Assim, para que se crie uma cultura de avaliação, considerando-a como um processo sistemático, gradativo e contínuo é necessário atentar para alguns fatores que influenciam no processo da avaliação.

\section{Fatores de maior constância presencial em resultados de avaliação}

Lopes (1997) afirma que a instituição educacional deverá se utilizar de referências de proceder coletivo, o equilibrio, o incentivo motivacional, o procedimento ético, 0 respeito às individualidades e o não reconhecimento da onipotência normativa, como forma de desenvolver potencialidades individuais dentro do contexto coletivo.

Essas potencialidades individuais são influenciadas pelo ambiente e por fatores responsáveis pelo comportamento do indivíduo.

Muitos são os fatores expostos por diversos autores, entretanto, alguns são vistos como potencialmente mais influentes no comportamento e atitude do ser humano.

Assim, em um ambiente de avaliação, fica clara a importância dos fatores, que de acordo com a pesquisadora foram classificados em:

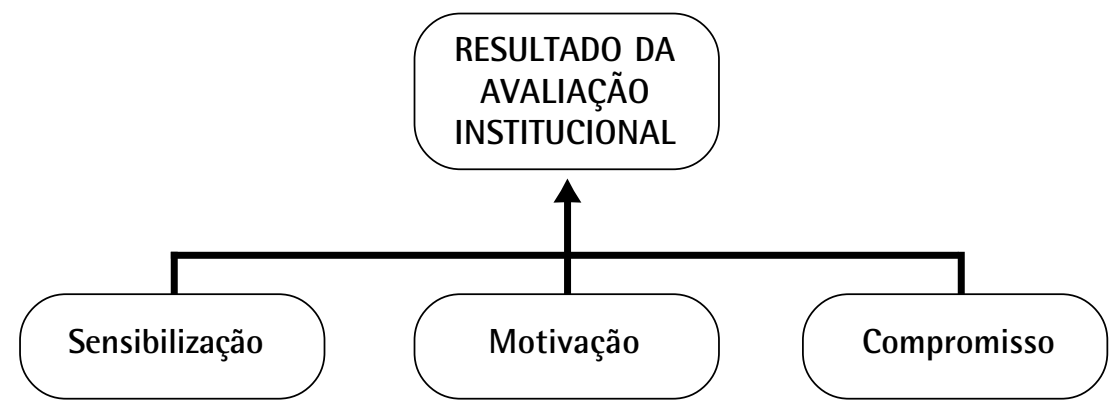

Figura 1. Fatores de maior constância presencial no resultado da avaliação. Fonte: Os autores (2009). 


\section{Sensibilização}

Sensibilização é o ato de se fazer emergir por antecipação do fato uma ambientação concernente ao desejo (LOPES, 1997).

A sensibilização pode ser vista como algo mais que a transmissão de informações; é criar condições diretas ou indiretas para que os atores envolvidos se insiram no processo de construção e compreensão das informações, bem como sua utilização no cotidiano institucional. Desejando alcançar este objetivo, a sensibilização do público de interesse deve ser realizada em todas as etapas do processo da avaliação.

A sensibilização, em um processo de avaliação, objetiva a participação e o envolvimento da comunidade acadêmica na construção e no desenvolvimento de uma proposta avaliativa através da realização de reuniões, palestras e seminários. Essa sensibilização deve estar presente em todos os momentos do processo avaliativo visando à continuidade das ações.

No contexto do ensino superior, no que se refere à avaliação institucional, a sensibilização por parte dos acadêmicos envolvidos deve intencionar construir um caminho direcionado à melhoria na qualidade do ensino, assim sendo, é de fundamental importância sensibilizar todos os envolvidos no processo

\section{Motivação}

Pontes (1986) afirma que para levar as pessoas a assumirem determinados tipos de comportamento é necessário motivá-las.

A motivação, para Chiavenato (1998), de maneira geral é tudo aquilo que impulsiona a pessoa a agir de determinada forma ou, pelo menos, que dá origem a uma propensão a um comportamento específico, podendo este impulso à ação ser provocado por um estímulo externo ou também ser gerado, internamente, nos processos mentais do indivíduo.

Portanto, a motivação pode ser entendida como um impulso que faz o ser humano agir quando se vê diante de um estado de necessidade, carência ou desequilibro e determina um movimento no sentido de evoluir do menos para o mais.

A motivação designa um conjunto de forças internas/impulsos que orientam o comportamento de um indivíduo para determinado objetivo como respostas a um estado de ncessidade, carência ou desequilíbrio de forças internas que mobilizam e orientam a ação de um organismo em direção a determinados objetivos como resposta a um estado de necessidade, carência ou desequilibrio. 
[...] a motivação é o conjunto de mecanismos biológicos e psicológicos que possibilitam o desencadear da ação, da orientação (para uma meta ou, ao contrário, para se afastar dela) e, enfim, da intensidade e da persistência: quanto mais motivada à pessoa está, mais persistente e maior é a atividade (LIEURY; FENOUILLET, 2000, p. 9).

As motivações sociais variam, conforme muda a cultura, pois resultam do processo de aprendizagem social. E é evidente que não pode ser estudada diretamente, pois se trata de uma experiência interna. Quanto mais motivada a pessoa está, mais persistente e maior é a atividade.

Vernon (1973) afirma que a motivação é encarada como uma espécie de força interna que emerge, regula e sustenta todas as ações mais importantes dos indivíduos. Contudo, é evidente que a motivação é uma experiência interna que não pode ser estudada diretamente.

Existem varias teorias da motivação, tentando explicar o porquê de os estímulos provocados gerarem respostas; o porquê de alguns estímulos terem valor de recompensa, enquanto que outros não; entre outras curiosas perguntas.

Para Lindgreen e Byrne (1982, p. 214-215),

as teorias da motivação são uma tentativa [...] de explicar porque: (1) os estímulos evocam respostas; (2) um determinado estímulo evoca uma certa resposta em vez de quaisquer outras concebíveis; (3) certos estímulos têm um valor de recompensa e outros não; (4) certas respostas parecem surgir por si mesmas, sem nenhum desencadeante exterior aparente.

A motivação é uma reação circunstancial que pode ser modificada a cada momento, dependendo dos objetivos do indivíduo. 


\begin{tabular}{|ll|}
\hline Autores & Definições \\
\hline Freud (1948) & $\begin{array}{l}\text { São seis os principios básicos da motivação: todo comportamento é moti- } \\
\text { vado; a motivação persiste ao longo da vida; os motivos verdadeiramente } \\
\text { atuantes são inconscientes; a motivação se expressa através de tensão; } \\
\text { existem dois motivos que prevalecem em face de sua possibilidade de re- } \\
\text { pressão (o sexo e a agressão) e os motivos têm natureza biológica inata. }\end{array}$ \\
\hline Atkison (1958) & $\begin{array}{l}\text { Motivação é a ativação de uma tendência que vai atuar para produzir } \\
\text { um ou mais efeitos. É o eu quero. }\end{array}$ \\
\hline Murphy (1961) & $\begin{array}{l}\text { Motivação é o nome geral que se dá atos de organismo que estão, em parte, } \\
\text { determinados por sua própria natureza ou por sua estrutura interna. }\end{array}$ \\
\hline McClelland (1971) & $\begin{array}{l}\text { Motivo ou motivação refere-se a um estado interno que resulta de uma } \\
\text { necessidade e que ativa ou desperta comportamento da necessidade ativante. }\end{array}$ \\
\hline Lopes (1980) & $\begin{array}{l}\text { Motivação é um estado interno que dá energia, torna ativo ou move o organis- } \\
\text { mo, dirigindo ou canalizando o comportamento em direção a objetivos. }\end{array}$ \\
\hline Nuttin (1981) & $\begin{array}{l}\text { Motivação é o processo pelo qual as necessidades se transformam em } \\
\text { fins, planos e projetos de ação. }\end{array}$ \\
\hline Merchantes (1984) & $\begin{array}{l}\text { Motivação é um conjunto de fatores dinâmicos que determinam a con- } \\
\text { duta de um indivíduo. }\end{array}$ \\
\hline Murray, E. J. (1986) & $\begin{array}{l}\text { Motivação é um fator interno que dá início, dirige e integra o comportamen- } \\
\text { to de uma pessoa. Não é diretamente observado, mas inferido do seu ou } \\
\text { parte-se do principio de que existe a fim de se explicar o seu comportamento. }\end{array}$ \\
\hline Campos (1989) & $\begin{array}{l}\text { Motivação é um processo interior, no individuo, que deflagra, mantem e } \\
\text { dirige o comportamento. Ela é um estado fisiopsicológico, interior ao indi- } \\
\text { motivos que o impelem a agir, com certo grau de intensidade e empenho. }\end{array}$ \\
\hline
\end{tabular}

Quadro 1. Algumas definições de motivação humana.

Fonte: Kinpara (2000, p. 20).

Com base nos conceitos acima, pode se verificar que a motivação é notadamente reconhecida como um fator não abstrato em qualquer atividade desenvolvida pelo ser humano.

\section{Compromisso}

0 compromisso é definido como "a força relativa da identificação do indivíduo com a organização e o seu envolvimento na mesma" (MOWDAY; PORTER; STEERS, 1982, p. 27).

Em uma instituição de ensino deve existir um envolvimento com a alta qualificação das atividades de pesquisa, cooperação, ensino e prestação de serviços para que o compromisso seja assegurado.

0 compromisso com a realidade de cada instituição se expressa na participação ativa no processo de desenvolvimento social, cultural e econômico, traduzida em ações institucionais definidas a partir das demandas e necessidades da comunidade acadêmica. 
Mesmo sendo muitas as definições e os modelos teóricos com relação ao comprometimento, constatou-se que os indivíduos agem de certa maneira para que possa contribuir para realização de algo, o objetivo visado, além de estarem influenciados pela vontade de demonstrar emoções positivas em relação ao ambiente que o cerca.

Segundo Dias Sobrinho (2003), a comunidade acadêmica constituída pelos docentes, discentes e funcionários técnico-administrativos, deve ter um compromisso institucional. Esse envolvimento deve ser tanto nas discussões sobre a concepção, as finalidades e o desenho da avaliação quanto também, do levantamento, da organização das informações e dos dados, das pesquisas e das interpretações que dão continuidade ao processo avaliativo.

\section{Procedimentos metodológicos}

Segundo Lopes e outros (2006, p. 171), uma investigação cientifica pode ser realizada de diversas formas e etapas, com o intuito de atingir a um determinado fim, de modo que a investigação seja organizada, segura, prática e verdadeira.

No desenvolvimento de toda pesquisa científica, buscam-se seguir caminhos que já foram explorados anteriormente. Segundo Vergara (2003, p. 12), o método é "um caminho, uma forma, uma lógica de pensamento"; portanto, o delineamento do caminho a ser percorrido na realização da pesquisa é extremamente importante para alcançar os objetivos desejados. Assim, nesse item, serão apresentados os métodos a serem adotados quando da execução do presente estudo.

\section{Caracterização da pesquisa}

Esta será uma pesquisa de natureza qualitativa, de caráter exploratório, que de acordo com Merriam (1998, p. 179), "é um conceito guarda-chuva cobrindo algumas formas de investigação que nos ajuda a entender e explicar o significado do fenômeno social com a menor quebra possivel do ambiente natural." Qualitativa porque, através da realização de entrevistas e observações, buscar-se-á conhecer a realidade da IES, para avaliar a dinâmica interna de processos e atividades, considerando suas características educacionais; e de enfoque exploratório-descritivo-explicativo, pois busca proporcionar maior conhecimento do problema com vistas a explicitá-lo, a descrever as características do objeto do estudo, bem como identificar os fatores ou variáveis que determinam ou que contribuem para a ocorrência dos fenômenos, isto é, suas causas.

Patton (2002, p. 14) afirma que o método qualitativo é uma ferramenta que facilita pesquisas de maior profundidade e com um maior nivel de detalhe. Merriam (1998) afirma que as pesquisas qualitativas buscam compreender a realidade do contexto a partir da visão de mundo dos indivíduos, sabendo-se que esta realidade é construída pela interação das pessoas com sua realidade social. 
As orientações para aplicabilidade do estudo qualitativo ocorrem porque essas se adaptam na busca de respostas às perguntas elaboradas cuidadosamente, na tentativa de compreender o fenômeno a partir da visão de cada respondente.

Portanto, a realização desta pesquisa implicou em um estudo aprofundado de um fenômeno particular, efetivado em uma única organização educacional. Nessa dimensão, este estudo caracteriza-se como um trabalho do tipo estudo de caso. Isso se justifica porque o estudo de caso ajuda a compreender fenômenos individuais e organizacionais, especialmente quando estes são complexos e contemporâneos.

\section{Delimitação da pesquisa}

\section{População, amostra e sujeitos de pesquisa}

A população ou universo da pesquisa, de acordo com Beuren (2006, p. 118), "é a totalidade de elementos distintos que possui certa paridade nas características definidas para determinado estudo" e que serão objeto de estudo.

Para Merriam (1998), existem dois tipos de amostra nos estudos qualitativos, a probabilística e a não probabilística. Entretanto, Merriam (1998) afirma que a não probabilística é a mais justificável na pesquisa qualitativa.

Segundo Biernacki e Waldorf (1981), uma das técnicas de amostragem é o snowball sampling, também conhecido por cadeia de informantes ou método bola de neve.

Nesta pesquisa, a amostra de sujeitos foi apoiada na técnica de "Bola de Neve" (Snowball) que permite a definição de amostra por referência, e o número de sujeitos foi definido utilizando os critérios de acessibilidade; experiência e envolvimento dos líderes em processos de avaliação institucional, o conhecimento, competências e habilidades sobre o objeto do estudo. Portanto, observando-se o universo da pesquisa, foram selecionados duas líderes formais da IES estudada.

De acordo com Vergara (2003), os sujeitos de pesquisa são as pessoas que nos fornecem os dados de que necessitamos e nessa pesquisa os sujeitos, objeto de estudo foram os "líderes formais" aqui tratados e representados pela Diretora de Avaliação e Planejamento e a coordenadora da Comissão Própria de Avaliação, da IES em estudo, por trabalharem diretamente com o processo da avaliação educacional.

\section{Estratégias de coleta}

Para Merriam (1998), os dados de caráter qualitativo consistem em citações diretas de pessoas sobre suas experiências, sentimentos, opiniões e conhecimentos, podendo ser coletadas através de entrevistas, observação e análise de documentos. 
Nesta investigação, na coleta de dados foram utilizadas a entrevista não estruturada, a pesquisa descritiva na forma de observação e a pesquisa bibliográfica, realizada em várias fontes como: livros, artigos, periódicos, internet etc.

A coleta foi realizada por intermédio da entrevistas não estruturada, porque, concordando com os autores Taylor e Bogdan (1984), é um tipo de coleta mais indicado quando se quer compreender as perspectivas dos respondentes sobre suas experiências e situações.

A observação, segundo Diehl e Tatim (2004, p. 71):

É uma técnica que permite obter dados de determinados aspectos da realidade. Não consiste apenas em ver e ouvir, mas também em examinar fatos ou fenômenos que se deseja estudar. Ajudar ao pesquisados a identificar e a obter provas a respeito de objetivos sobre os quais os individuos não têm consciência, mas orientam seu comportamento.

Os dados advindos da pesquisa bibliográfica serão analisados, interpretados e apresentados através da fundamentação teórica.

Esses procedimentos são fundamentalmente viáveis para garantir a qualidade dos resultados, das entrevistas, das observações e da pesquisa bibliográfica, realizada nos processos da pesquisa.

Portanto, para que ocorra a pesquisa, é necessário coletar os dados e, posteriormente, interpretá-los e analisá-los para garantir as observações e a qualidade dos resultados.

Inicialmente, realizou-se uma pesquisa exploratória, intencionando conhecer quais líderes formais estariam, substancialmente, preparados para responder as perguntas uma vez que tais perguntas são muito especificas no que tange a avaliação institucional. Durante a pesquisa exploratória, as maiorias dos líderes formais abordados não se acharam preparados para responder a entrevista e, por unanimidade, indicaram uma professora que hoje ocupa uma função administrativa, ligada à área da avaliação institucional e que poderia responder as perguntas atendendo ao propósito do trabalho.

A partir dai, procurou-se contatar a professora, que atendia os critérios definidos pela pesquisadora, para agendamento da entrevista. 0 contato foi realizado e de imediato ela se propôs a receber a pesquisadora. A entrevista aconteceu na própria IES estudada, no ambiente da professora. A referida professora, com a intenção de colaborar com a pesquisadora, indicou outro líder formal, que também se enquadrava nos critérios definidos para os sujeitos da pesquisa, uma professora, que é lotada no Centro de Educação, e hoje é coordenadora da CPA. Foi feito o contato com a coordenadora da CPA, e a mesma se dispôs prontamente a responder as questões da pesquisadora. 
As entrevistas foram gravadas, cada entrevista teve em média a duração de 45 minutos e as entrevistadas se mostraram interessada em responder todas as questões de maneira completa e clara, descrevendo suas visões sobre fatores que incidiram no resultado do ENADE.

Neste sentido, foram selecionados dois grupos de análise para que pudéssemos utilizar parâmetros nas reflexões acerca dos dados. São eles: finalidade do ENADE e fatores que interferem nos resultados do ENADE. Dessa forma, buscou-se apreender das entrevistas realizadas, como esses grupos são compreendidos e como têm sido materializadas no cotidiano da avaliação.

\section{Validade e confiabilidade}

Para Merriam (1998), os estudos quantitativos buscam atingir um nivel de validade e confiabilidade através do uso de dados estatísticos, das variáveis bem definidas, distintamente da pesquisa qualitativa que utiliza critérios que tornam a pesquisa confiável.

Os critérios utilizados para levar o estudo a uma validação e confiabilidade adequadas dizem respeito ao questionamento de como os resultados da pesquisa estão compativeis com a realidade. 0 estudo qualitativo visa ao entendimento dos significados construídos pelos respondentes com base em suas experiências, entretanto, validar a realidade é algo bastante complexo, por ser a realidade algo bastante mutável.

Pesquisadores como Merriam (1998) e Yin (2001) discutem formas que possibilitem maior robustez à validação interna do estudo. São elas: a triangulação de múltiplas fontes de dados; verificação dos dados interpretados pelos respondentes; e a orientação teórica embricada com o estudo proposto. Nesse estudo adotaramse a checagem da análise dos dados pelas entrevistadas e o arcabouço teórico que possibilitou uma análise do fenômeno.

Portanto, foram encaminhados às entrevistadas os achados da pesquisa com a finalidade das respondentes, se acharem necessárias, fazerem algumas alterações para retratar fielmente a realidade apresentada pelas respondentes no momento da entrevista.

Com relação à validação externa, que é a capacidade de o estudo poder ser transferido para outras situações (MERRIAM, 1998), nesta pesquisa buscou-se descrever, detalhadamente, o fenômeno estudado para dar possibilidade ao leitor de avaliar se as situações e os achados apresentados no texto possam ser transferidos para outras realidades.

Quanto à confiabilidade que se refere ao grau em que um estudo pode ser replicado futuramente em outras realidades, por outros pesquisadores, utilizando-se os mesmos procedimentos de maneira a alcançar os mesmos resultados, este estudo, certamente, poderá ser replicado em outras IES com seus respectivos líderes formais. 


\section{Análise das respostas}

A etapa da análise das respostas ou análise dos dados segundo Patton (2002) é onde os dados são analisados objetivando transformá-los em resultados. Esses resultados, no estudo qualitativo, englobam os procedimentos de descrição e análise.

Neste estudo, utilizou-se a análise do discurso que, para Vergara, (2003) é a análise recomendada quando se quer mostrar a maneira como se diz alguma coisa, quando envolve algo mais do que saber o que se fala, envolve saber quem fala, para quem fala, como fala e para que fala, pois o discurso pode ter várias funções e significados.

A análise dos dados é tarefa bastante complexa onde o pesquisador trilha entre os dados e conceitos, descrevendo-os e interpretando-os.

Durante a análise do discurso, os dados foram sistematicamente comparados, considerando pontos destacados pelos respondentes, como repetições de expressões, palavras, ideias, reflexões e posicionamentos acerca do objeto do estudo.

\section{Análise dos resultados}

As entrevistas buscaram explorar questões sobre a visão de profissionais que atuam na área da avaliação institucional da IES e a partir das respostas obtidas sobre "perfil dos líderes formais", as entrevistadas podem ser consideradas confiáveis pela experiência que as respondentes têm ocupando cargos de chefia - em coordenação de curso, chefia departamental, coordenação da CPA e a diretoria de avaliação e planejamento. Isso dá às líderes formais uma segurança e um conhecimento aprofundado sobre o objeto do estudo.

\begin{tabular}{|l|l|l|l|l|}
\hline NOME & $\begin{array}{l}\text { TEMPO DE } \\
\text { DOCÊNCIA }\end{array}$ & TITULAÇÃO & $\begin{array}{l}\text { REGIME DE } \\
\text { TRABALHO }\end{array}$ & $\begin{array}{c}\text { CARGOS DE CHEFIA } \\
\text { OCUPADOS }\end{array}$ \\
\hline Entrevistada 1-E1 & $\begin{array}{l}6 \text { anos de IES } \\
19 \text { anos de } \\
\text { ensino }\end{array}$ & Doutora Economia & T40-DE & $\begin{array}{l}\text { Coordenadora de curso; } \\
\text { chefia de departamento; } \\
\text { coordenadora de CPA; } \\
\text { diretoria de Avaliação } \\
\text { e Planejamento }\end{array}$ \\
\hline Entrevistada 2-E2 & $\begin{array}{l}15 \text { anos IES } \\
\text { eno anos de } \\
\text { ensino }\end{array}$ & Doutora em Educação & T 40-DE & $\begin{array}{l}\text { Coordenadora da divisão } \\
\text { de avaliação docente; } \\
\text { chefe de departamento; } \\
\text { membro e coordenadora } \\
\text { da CPA }\end{array}$ \\
\hline
\end{tabular}

Quadro 2. Perfil das líderes formais.

Fonte: Os autores (2010).

Analisando os resultados da pesquisa, um ponto que merece destaque é que as profissionais entrevistadas veem o ENADE como um componente da avaliação ins- 
titucional que, como afirma Goldemberg (1992) vem sendo visto como um instrumento competente para promover a melhoria do ensino nos cursos das IES. As entrevistadas afirmaram que:

"É um acompanhamento para avaliação da qualidade dos cursos, uma das formas de mensurar o desempenho do aluno".

"É visto como instrumento necessário para promover a qualificação institucional, promovendo a melhoria do ensino, da pesquisa, da extensão e da sua gestão".

"Através do ENADE é possivel dar feedback para o estudante e auxiliá-lo de modo a resolver a questão do domínio do conteúdo das disciplinas do curso".

Outro aspecto interessante que se pode destacar é que, no processo de avaliação institucional, as atividades desenvolvidas pela instituição ao longo das avaliações sofrem interferência de fatores que transcendem o controle das líderes formais. Quanto a esse aspecto as respondentes afirmaram que:

"Há fatores que fogem ao nosso controle [...], fatores como a sensibilização dos alunos, a motivação e o compromisso no processo de realização do ENADE".

"Os resultados obtidos no ENADE também fazem parte do processo de sensibilização. Com os resultados em mãos, fazemos um trabalho de sensibilização junto aos alunos e demais atores envolvidos".

Quando se questionou sobre quais as iniciativas tomadas para sensibilizar os alunos a participarem de maneira espontânea do ENADE, as entrevistadas responderam que:

"Em um primeiro momento, foram realizadas reuniões de sensibilização com as coordenações de cursos e lideranças administrativas. Também foram envolvidos representantes docentes e discentes, além dos membros das Comissões Setoriais de Avaliação".

0 fator destacado pelas entrevistadas foi a motivação e quanto a esse fator, ficou explícito que os alunos não se sentem motivados em realizar/participar do ENADE e que os mesmos só comparecem porque são obrigados.

"Os alunos não se sentem motivados, na verdade se sentem obrigados a fazerem o ENADE e que essa obrigação pode trazer prejuizos para eles".

Quando foi questionado sobre o que poderia ser feito para motivar esses alunos a participarem do ENADE de maneira mais espontânea, foi dito que: 
"Através do processo de conscientização junto aos alunos, mostrando para eles que se o resultado do EANDE for positivo, ganha ele e ganha à universidade".

"Que se a universidade sai com nota excelente, todos terão orgulho de serem ou de terem sido alunos da universidade".

Com relação ao compromisso que os alunos têm com relação ao ENADE, ficou claro que os alunos, na sua grande maioria, não estão comprometidos com esse exame, que fazem porque é uma exigência do MEC. Nesse item, as entrevistadas afirmaram que:

"Os alunos que fazem o ENADE são aqueles que são selecionados pelo MEC e só comparecem ao exame porque eles são obrigados, e se não fizerem não colam grau e consequentemente não recebem o diploma".

"Os alunos não assumem o compromisso natural de que devem fazer o ENADE. Muito pelo contrário, em um dos cursos, aqui da IES, dos 24 alunos que fizeram 0 ENADE, apenas seis responderam a prova, o restante deixou a prova em branco, interferindo negativamente no resultado".

\section{Limitações do estudo}

Vale salientar que os resultados obtidos são restritos aos indivíduos selecionados e não podem ser generalizados, estatisticamente, para todos os líderes formais.

\section{Conclusão}

0 estudo mostrou que o processo de avaliação institucional da IES, no que se refere ao ENADE, enquanto atividade imposta pelo MEC/INEP pode ser visto como um instrumento importante de melhoria da qualidade do Ensino Superior, e impulsiona à construção de uma universidade produtora e crítica, levando à satisfação ou insatisfação de seus os alunos, professores e funcionários (GOLDEMBERG, 1992).

Pôde-se perceber que o ENADE implica em mudança, buscando avaliar o processo e não o produto, e permitindo a correção e superação de dificuldade. Entretanto, não há, por parte da maioria dos alunos, interesse neste exame, e, talvez, esse interesse venha a acontecer com a implementação de uma cultura de avaliação. Para que essa cultura seja incorporada à IES é necessário alertar para a sua importância e vencer as resistências e os temores com relação ao processo de avaliação (FAÚNDEZ, 1999).

0 contexto possibilitou identificar alguns fatores que interferem no resultado do ENADE. Desta maneira, os achados reforçam que, dentre os muitos fatores importantes para obter-se um resultado satisfatório no ENADE, a sensibilização, a motivação e o compromisso dos alunos com o ENADE são tidos como os mais significativos na visão das líderes entrevistadas. 
Contudo, observou-se que o resultado revela que, mesmo com situações desgastantes provenientes dos fatores que interferem no resultado do ENADE, isso não impede que se criem alternativas para que a prática avaliativa seja efetivada, desejando uma educação de qualidade.

Então, é basilar a compreensão de que os fatores referenciados neste estudo de avaliação seletiva específica do discente interferem nas questões avaliativas internas e externas da IES em estudo, e afetam o processo de construção do saber.

\section{Referências}

BEUREN, I. M. et al. Como elaborar trabalhos monográficos em contabilidade. São Paulo: Atlas, 2006.

BIERNACKI, P.; WALDORF, D. Snowball sampling: problems and techniques of chain referral sampling. Sociological Methods \& Research, Thousand Oaks, CA, v. 10, n. 2, 1981.

BRASIL. Lei $n^{0} .10 .861$, de 14 de abril de 2004. Institui o Sistema Nacional de Avaliação da Educação Superior - SINAES e dá outras providências. Disponivel em: <http://www.puc-rio.br/sobrepuc/depto/ccpa/cpa/docs/ lei_SINAES_042004.pdf>. Acesso em: 12 jun. 2009.

. Ministério da Educação. Portaria nº. 2.051, de 9 de julho de 2004. Regulamenta os procedimentos de avaliação do Sistema Nacional de Avaliação da Educação Superior (SINAES), instituído na Lei nº. 10.861, de 14 de abril de 2004. Diário Oficial da União, Brasilia, DF, 12 jul. 2004. Seção 1, p. 12.

CENTRO FEDERAL DE EDUCAÇÃO TECNOLÓGICA DE PELOTAS (RS). Histórico da instituição. Pelotas, [2005?]. Disponivel em: <http://www.cefetrs.tche.br/ comunidade/documentos/pdi_total.pdf>. Acesso em: 9 jun. 2011.

CHIAVENATO, I. Recursos humanos. 5. ed. São Paulo: Atlas, 1998.

DIAS SOBRINHO, J. Avaliação da educação superior: regulação e emancipação. . Avaliação: revista da avaliação da educação superior, Campinas, SP, ano 8, v. 8, n. 2, p. 31-47, 2003.

Avaliação institucional: marcos teóricos e políticos. Avaliação: revista da avaliação da educação superior, Campinas, SP, v. 1, n. 1, p. 15-24, 1996.

DIEHL, A. A.; TATIM, D. C. Pesquisa em ciências sociais aplicadas: métodos e técnicas. São Paulo: Prentice Hall, 2004. 
FAÚNDEZ, C. O. Hacia la creación de una cultura de la evaluación como garantia de calidade de las universidades. Avaliação: revista da avaliação da educação superior, Campinas, SP, v. 4, n. 1, p. 35-41, mar. 1999.

GOLDEMBERG, J. 0 impacto da avaliação na universidade. In: DURHAM, E. R.; SCHWARTZMAN, S. (Org.). Avaliação do ensino superior. São Paulo: EdUSP, 1992.

KINPARA, M. M. Motivação humana: motivos envolvidos no processo educacional na UFAC. 2000. Tese (Doutorado em educação) - Faculdade de Educação, Universidade Estadual de Campinas, Campinas, SP, 2000. Disponivel em: <http:// www.scribd.com/doc/6797271/Motivacao-Humana>. Acesso em: 15 jul. 2009.

LIEURY, A.; FENOUILLET, F. Motivação e aproveitamento escolar. Tradução de Y. M. C. T. Silva. São Paulo: Loyola, 2000.

LINDGREEN, H. C.; BYRNE, D. Psicologia: processos comportamentais. Rio de Janeiro: LTC, 1982.

LOPES, J. Uma introdução ao estudo da escola do terceiro milênio: a escola contingencial. Revista de Administração Educacional, Recife, v. 1, n. 1, p. 39-45, jul./dez. 1997.

LOPES, J. et al. O fazer do trabalho científico nas ciências sociais aplicadas. Recife: Ed. UFPE, 2006.

MERRIAM, S. Qualitative research and case study application in education. San Francisco: Jossey-Bass, 1998.

MOWDAY, R. T.; PORTER, L. W.; STEERS, R. M. Employee-organization linkages: the psychology of commitment, absenteism and turnover. New York: Academic Press, 1982.

OLIVEIRA, R. A avaliação de curso: uma dimensão da Universidade. Revista ADUSP, São Paulo, n. 18, p. 30-35, out. 1999.

PATTON, M. Q. Qualitative research and evalution methods. 3. ed. London: Sage, 2002.

PONTES, B. R. Avaliação de desempenho: uma abordagem sistêmica. São Paulo: LTr, 1986.

RISTOFF, D. I. Universidade em foco: reflexões sobre a educação superior. Florianópolis, SC: Insular, 1999. 
TAYLOR, S.; BOGDAN, R. Introduction to qualitative research methods: the search for meanings. 2. ed. New York: John Wiley and Sons, 1984.

TRIGUEIRO, M. G. S. 0 modelo CIPP para a avaliação institucional da universidade de Brasilia. In: SEMINÁRIO BRASILEIRO SOBRE AVALIAÇÃO UNIVERSITÁRIA, 1995, Campinas. Anais ... Campinas, SP: UNICAMP/FE/GEPES, 1995.

VERGARA, S. C. Projetos e relatórios de pesquisa em administração. 4. ed. São Paulo: Atlas, 2003.

VERNON, M. D. Motivação humana. Tradução de L. C. Lucchetti. Petrópolis: Vozes, 1973.

YIN, R. K. Estudo de caso: planejamento e métodos. 2. ed. Porto Alegre:

Bookman, 2001.

Recebido em: 20/09/2010

Aceito para publicação em: 17/02/2011 